\title{
Influence of segregation on the performance of self-compacting concrete in the fresh and hardened states
}

\author{
Mohammed Krachaï R 1,2, Bouabdallah M A 3,4,*
}

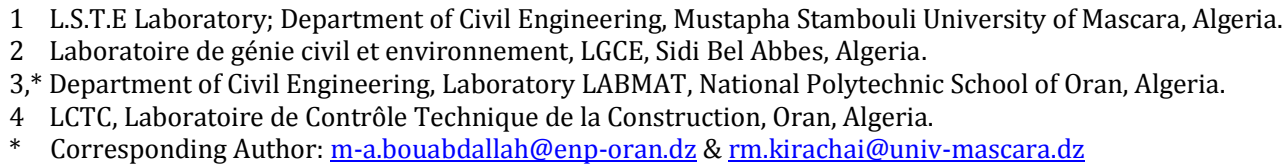

Received: 12-08-2020

Accepted: 18-09-2020

\begin{abstract}
The granular mixture represents one of most important parameters in the formulation of self-compacting concretes in order to achieve a representative granular distribution. A good resistance to segregation results in a regular distribution of the different sizes of the aggregates in all parts of the element, with the same granule density. The granular mixture must be homogeneous and representative, and has to be able to flow in the absence of dynamic and static segregation.

The main objective of the present research is to study the influence of segregation on the performance of Self-compacting concrete in the fresh and hardened state, by determining the static segregation index according to the percentage of aggregates of class $\mathrm{G} 8 / 15$ and that of aggregates of class $\mathrm{G} 3 / 8$ in order to obtain a homogeneous granular mixture, whatever the volume of self-compacting concrete to be prepared. It is well acknowledged that the threshold of the discontinuation of granular mixing represents a new element with respect to segregation in concrete. The obtained results showed that the percentage of large aggregates has a significant influence on the segregation index and the performance of selfcompacting concrete (SCC) at 28 days.
\end{abstract}

Key words: Self-compacting concrete, Segregation index, Granular mixture, Fresh state test, hardened state test.

\section{Introduction}

Self-compacting concretes are hyper-fluid concretes that can be placed, without vibration, under the effect of their own weight and because of their flow characteristics. These concretes must have a high fluidity and be able to flow with a sufficient flow rate, without external energy supply, through confined areas even in the presence of obstacles; they can also be placed in tall formworks. Concretes must oppose dynamic segregation in the pouring phase, and static segregation, once in place, in order to guarantee the homogeneity of the characteristics and to avoid bleeding or compaction. Good resistance to segregation results in a regular distribution of coarse aggregates in all parts of the element and at all levels.

Therefore, concrete must not undergo any form of horizontal and vertical segregation. The formulation of self-compacting concrete is based on three criteria, i.e. fluidification of concrete paste, limitation of friction between the aggregates in order to promote the flow and stabilization of the mixture, and prevention of segregation in concrete.

Among the publications and methods presented by some authors on SCC segregation, one may cite the procedure of Sidky et al. (1981), the Japanese cylinder method by Umehara et al. (1994), the column test developed by Otsuki et al. (1996), the Japanese metal pallet method by Tangtermsirikul et al. (1991), the column test through the measurement of the electrical resistivity of fresh concrete developed by Yim (2020), the sieve method of Fujiwara (1992), the method proposed by Bui et al. (2002), and the ball penetration test developed by Trudel (1995). 
Similarly, Shen et al. (2014) established a new method for measuring the static segregation which is based on the two Standards: ASTM C1712-09 (2009) and C1610 / C1610 M-10 (2010). Moreover, Bensebti (2015) used a very simple test that allows for the direct assessment of static segregation in self-compacting concretes (SCCs). The results obtained by this author indicated that it is possible to obtain a good SCC, it would be necessary to have a lower static segregation coefficient that is less than or equal to 5. The objective of the present article is to study the behavior of segregated self-compacting concretes with the objective of obtaining a homogeneous and representative granular mixture in the fresh and hardened state.

\section{Experimental study}

\subsection{Used materials}

Portland cement type CEM II A 42.5 was used, with limestone gravel 0/3, 3/8 and 8/15 mm and siliceous sea sand $0 / 1 \mathrm{~mm}$; wood waste and water were subsequently added.

Table 1. Characteristics of the used cement

\begin{tabular}{|c|c|c|c|c|}
\hline Identification & Cement class & Type of addition in cement & Clinker \% & Density \\
\hline \hline CEM II & CEMII/42.5 A & Pouzzolanique (6-20\%) & $80-94 \%$ & 3,1 \\
\hline
\end{tabular}

Table 2. Characteristic of the materials used

\begin{tabular}{|c|c|c|c|c|c|}
\hline \multicolumn{2}{|l|}{ Test } & Gravel 8/15 mm & Gravel 3/8 mm & Crushed sand & Sea sand \\
\hline \multicolumn{2}{|l|}{ Densities [g/cm $\left.{ }^{3}\right]$} & 2,735 & 2,727 & 2,714 & 2,642 \\
\hline \multicolumn{2}{|c|}{ Absorption Coefficients } & 1,52 & 1,75 & 2,65 & 2,11 \\
\hline \multicolumn{2}{|l|}{ Los Angeles } & \multicolumn{2}{|c|}{23,56} & - & - \\
\hline \multirow{2}{*}{$\begin{array}{l}\text { Sand Equivalent } \\
\text { Test [\%] }\end{array}$} & ESV & - & - & 76,86 & 72 \\
\hline & ESP & - & - & 70,53 & 67,69 \\
\hline
\end{tabular}

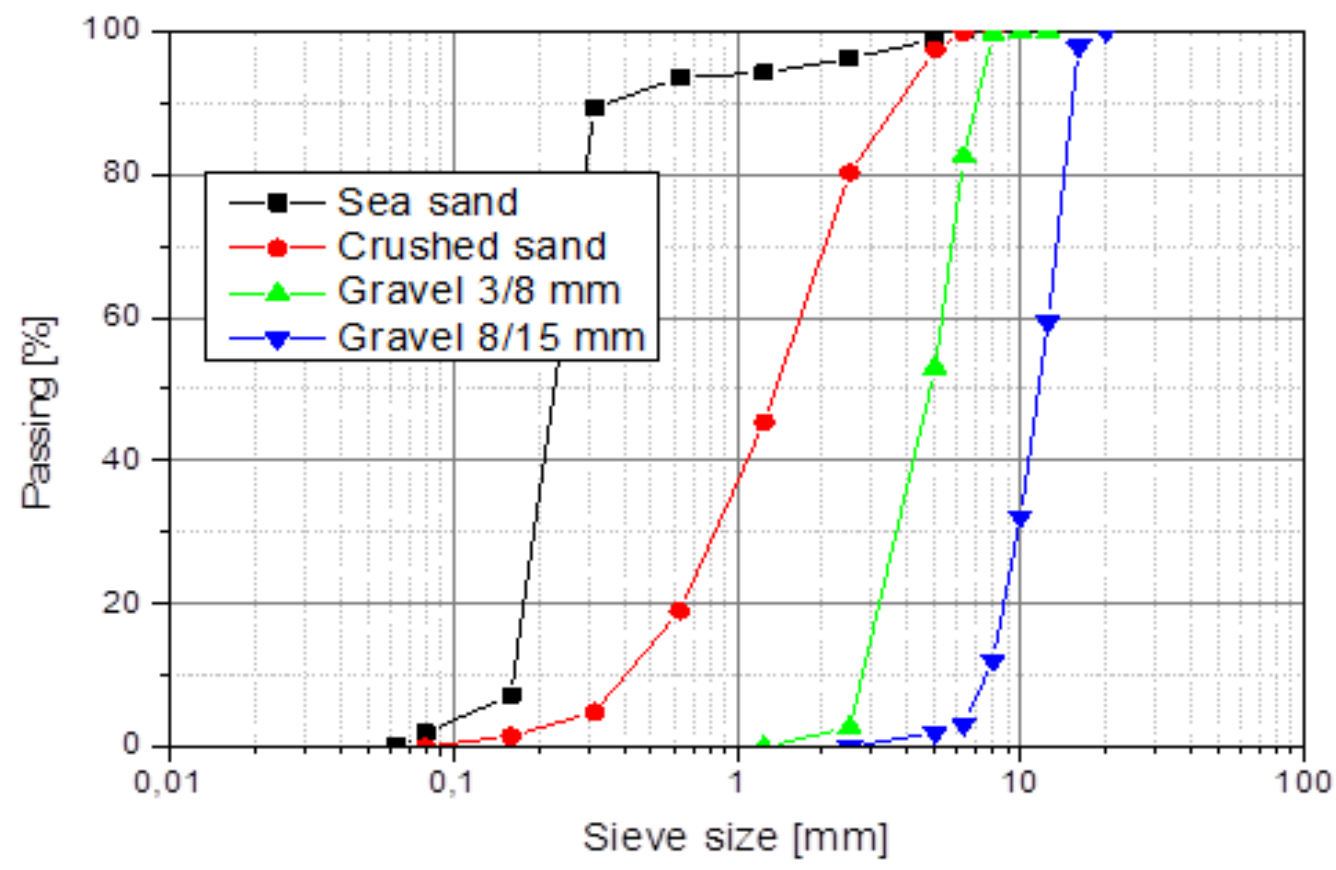

Fig 1. Particle size of the used aggregates.

\subsection{Formulation of concretes}

Table 3 illustrates the composition of the different types of Self-compacting concrete (SCC). 
Table 3. Concrete compositions of different types of Self-compacting concrete (SCC).

\begin{tabular}{|c|c|c|c|c|c|c|c|c|c|c|c|}
\hline $\begin{array}{c}\text { Constituents } \\
(\mathrm{Kg} / \mathrm{m} 3)\end{array}$ & B01 & B02 & B03 & B04 & B05 & B06 & B07 & B08 & B09 & B10 & B11 \\
\hline \hline $\begin{array}{c}\text { Gravel 8/15 } \\
\text { mm }\end{array}$ & 0 & 81,5 & 163 & 244,5 & 326 & 407,5 & 489 & 570,5 & 652 & 733,5 & 815 \\
\cline { 2 - 14 } & $0 \%$ & $10 \%$ & $20 \%$ & $30 \%$ & $40 \%$ & $50 \%$ & $60 \%$ & $70 \%$ & $80 \%$ & $90 \%$ & $100 \%$ \\
\hline $\begin{array}{c}\text { Gravel 3/8 } \\
\text { mm }\end{array}$ & 815 & 733,5 & 652 & 570,5 & 489 & 407,5 & 326 & 244,5 & 163 & 81,5 & 0 \\
\cline { 2 - 14 } & $100 \%$ & $90 \%$ & $80 \%$ & $70 \%$ & $60 \%$ & $50 \%$ & $40 \%$ & $30 \%$ & $20 \%$ & $10 \%$ & $0 \%$ \\
\hline Crushed sand & 244 & 244 & 244 & 244 & 244 & 244 & 244 & 244 & 244 & 244 & 244 \\
\hline Sea sand & 562 & 562 & 562 & 562 & 562 & 562 & 562 & 562 & 562 & 562 & 562 \\
\hline Cement & 400 & 400 & 400 & 400 & 400 & 400 & 400 & 400 & 400 & 400 & 400 \\
\hline SP (\% Cement) & 10 & 10 & 10 & 10 & 10 & 10 & 10 & 10 & 10 & 10 & 10 \\
\hline water & 206 & 206 & 206 & 206 & 206 & 206 & 206 & 206 & 206 & 206 & 206 \\
\hline
\end{tabular}

\subsection{Tests methods for measuring SCC characteristics and Properties}

A number of tests were conducted in accordance with the recommendations of the French Association for Civil Engineering (AFGC, 2008).

- $\quad$ Slump Flow Concrete Test (fig 2), NF EN 12350-8 (2019).

- $\quad$ L-box test (fig 3), NF EN 12350-10 (2010).

- $\quad$ Sieve segregation test (fig 4), NF EN 12350-11 (2010).

- $\quad$ Column test (fig 5) (ASTM C1610). (2010)

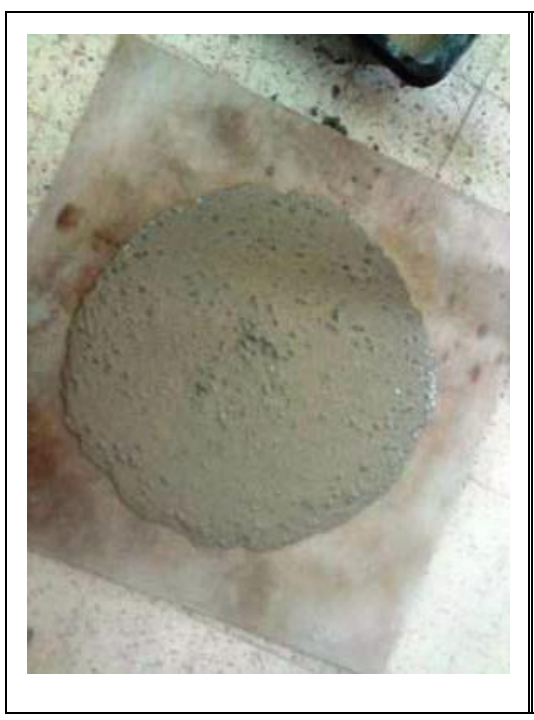

Fig 2. Slump Flow Concrete Test

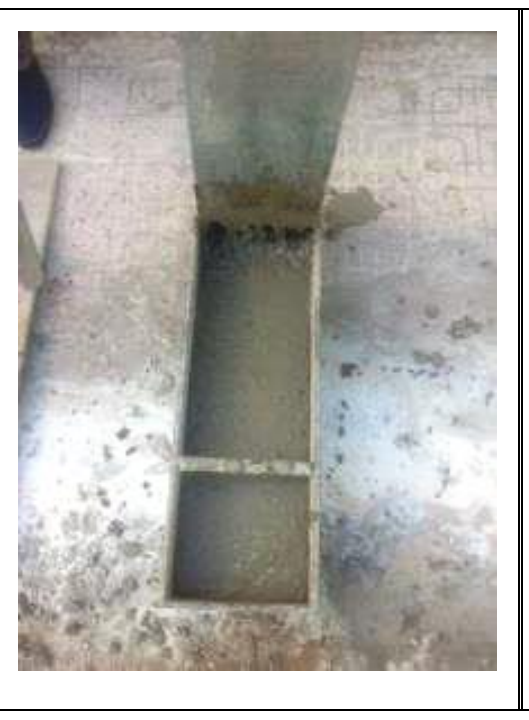

Fig 3. L-box test

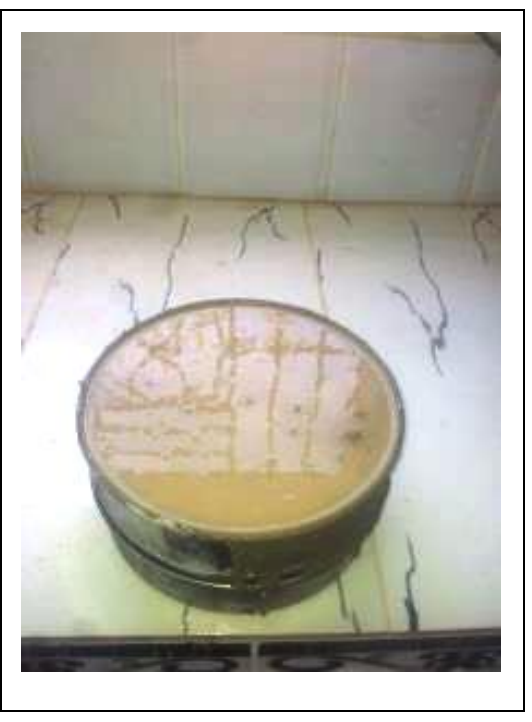

Fig 4. Sieve segregation test

The column test for the measurement of SSI is illustrated in Figure 5. The advantage of this column test lies in the fact that the operation of separation of the different concrete layers takes place after complete stabilization of the granular system. This column test offers a great advantage to the operator in preventing the concrete to flow. In this case, errors due to loss of the material during the separation and weighing procedures are therefore relatively small. 


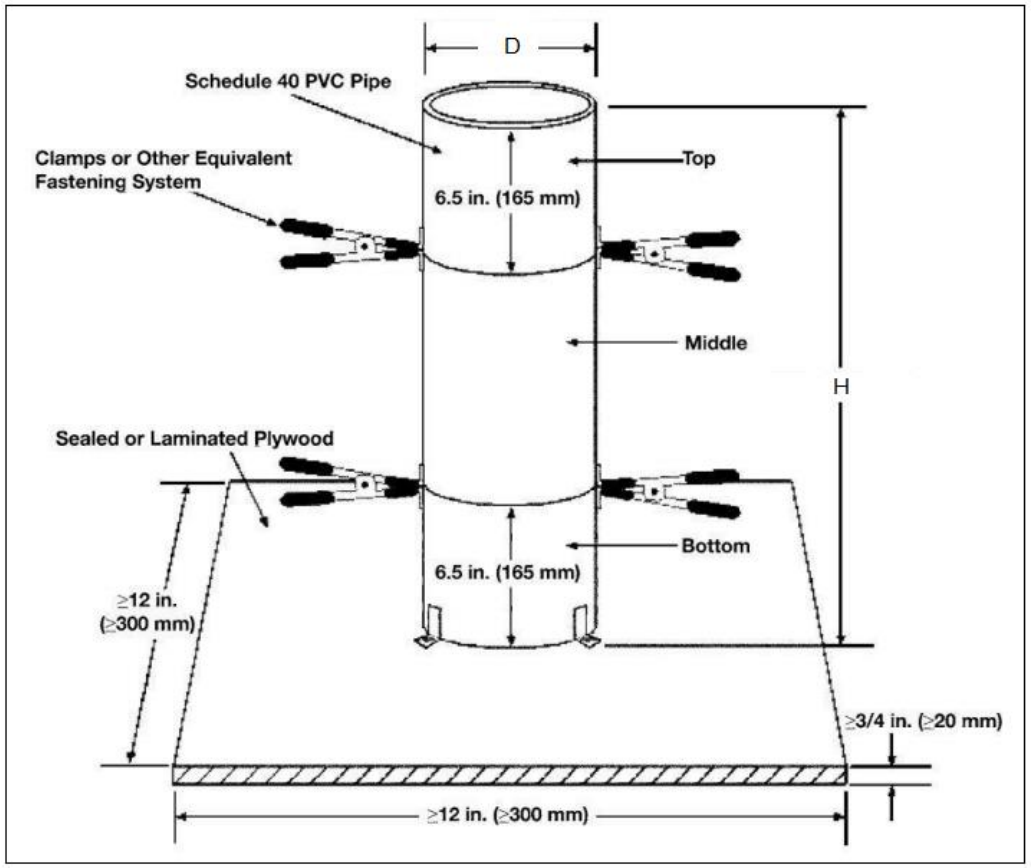

Fig 5. Column test (ASTM C1610).

\subsection{Description of the column test and methodology used}

The different stages of this proposed test are presented in the following and are illustrated in Figure 6.

- The mold used is a cylinder with a diameter $\mathrm{D}=110 \mathrm{~mm}$ and height $\mathrm{H}=400 \mathrm{~mm}$.

- First, the concrete was poured into the mold in a single operation to a height of $20 \mathrm{~cm}$.

- Once the mold was filled, it was leveled off using a metal ruler.

- The waiting time was close to the concrete setting time.

- The mold was then separated into three more or less equal parts (upper part, middle part and lower part).

- After weighing, washing and drying of each part, the ratio of the mass of dry aggregates (> $5 \mathrm{~mm}$ ) to the total mass was determined. The aggregate contents of each part (upper $\mathrm{G}$, middle $\mathrm{G}$ and lower $\mathrm{G}$ ) were then calculated using the ratio of the mass of dry aggregates to the total mass of the part under consideration.
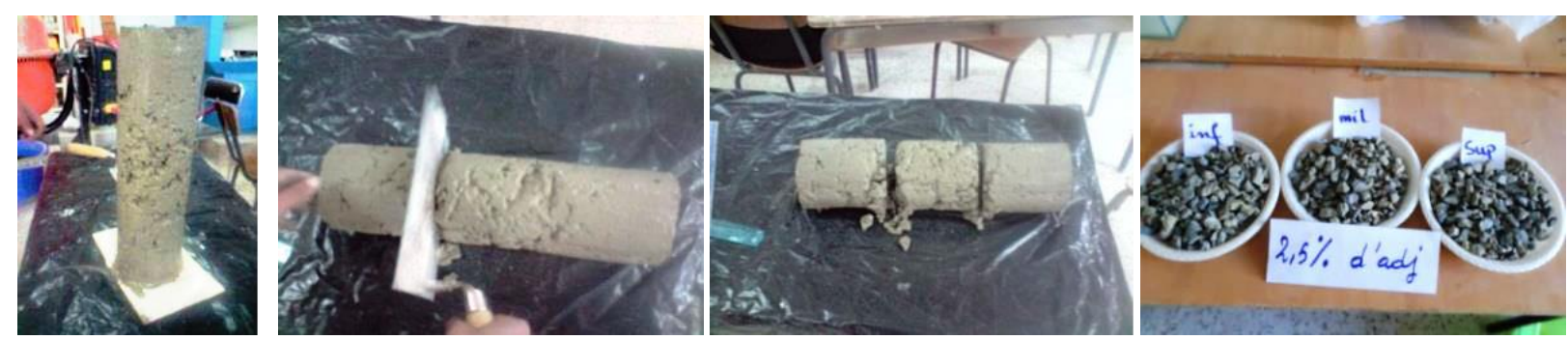

Fig 6. Column test with the different steps to measure (SSI).

It is worth knowing that the static segregation index is defined as follows:

$$
I S S=\left(G_{\text {inf }}-G_{\text {sup }}\right) \times 100
$$




\section{Results and discussion}

\subsection{Analysis of fresh state behavior of self-compacting concrete}

Figure 7 shows the influence of the percentages of gravels $3 / 8$ and $8 / 15$ on the segregation index. It should be noted that increasing the amount of gravel G 8/15 and decreasing that of $G$ $3 / 8$ increases the risk of static segregation.

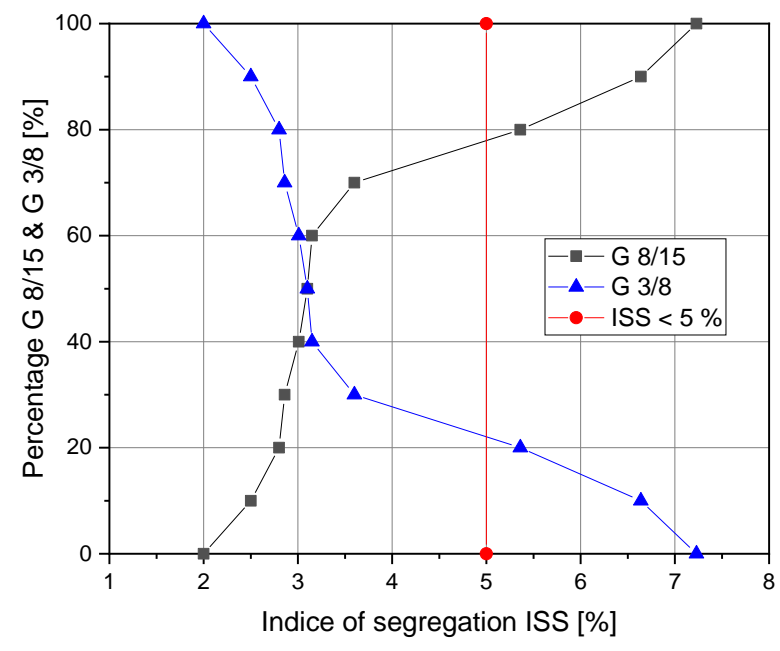

Fig 7. Percentages of $\mathrm{G} 8 / 15$ and $\mathrm{G} 3 / 8$ as a function of the static segregation index.

Figure 8 shows the evolution of SSI as a function of concrete spread, for all the formulations from B1 to B11. The behavior of the concretes tested (from B2 to B8) varied with (SSI $(\%)<5$ ) which ensures that these concretes have a sufficient spread so they can be classified as selfcompacting concretes, according to the French Standard NF 206. On the other hand, the granular mixtures B6, B7 and B8 exhibited a spread greater than $60 \mathrm{~cm}$, with no segregation phenomenon.

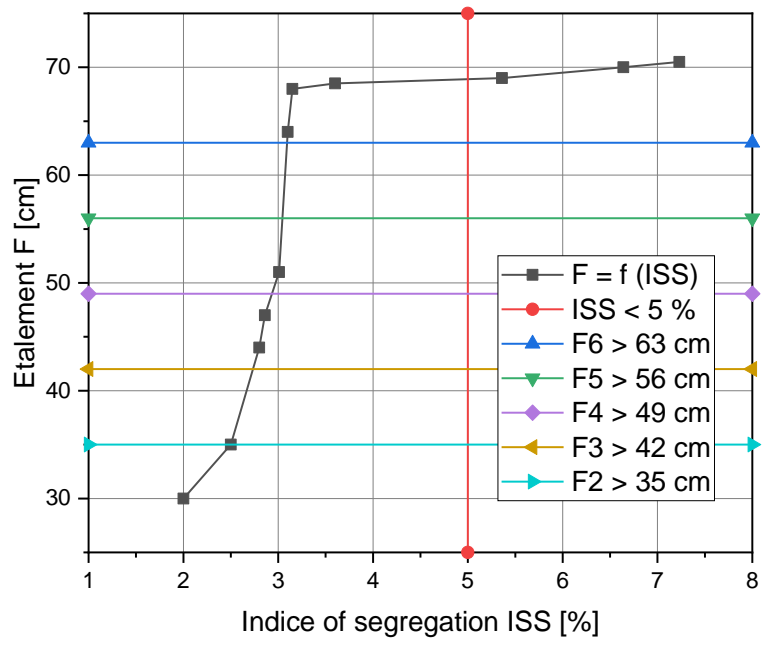

Fig 8. Evolution of the concrete spread as a function of the static segregation index. 
On the other hand, Figure 9 displays the results of the L-box test as a function of segregation. The variation of the ration $\mathrm{H} 2 / \mathrm{H} 1$ as a function of segregation suggested that there was a high filling rate that was greater than or equal to 0.80 for the granular mixtures B6, B7 and B8. It is also worth noting that concrete passing ability increased as the percentage of $\mathrm{G} 8 / 15$ became more important than that of $\mathrm{G} 3 / 8$. It is interesting to mention that the specific surface area of aggregates G 3/8 was greater than that of G 8/15 aggregates, which had an influence on the absorption of mixing water.

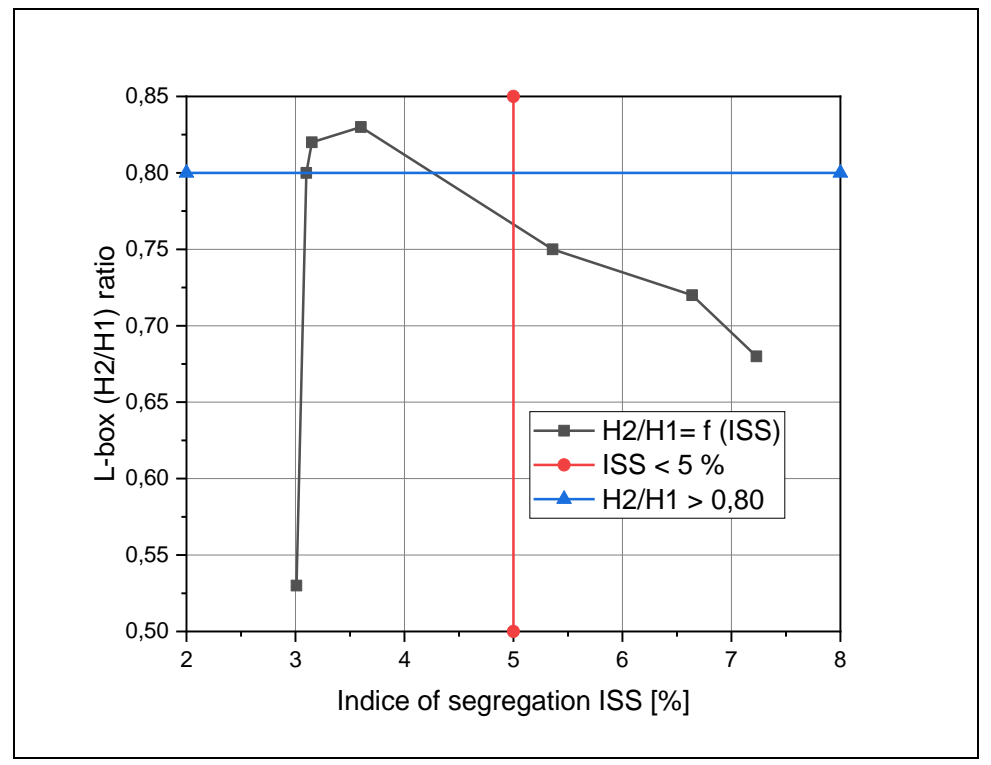

Fig 9. Evolution of the ration $\mathrm{H} 2$ / $\mathrm{H} 1$ as a function of the static segregation index.

Figure 10 represents the results of the sieve stability test as a function of static segregation. Note that the coefficient $\pi$ represents the percentage of laitance relative to the weight of concrete. It is worth emphasizing that the coefficient $\pi$ must be less than $15 \%$.

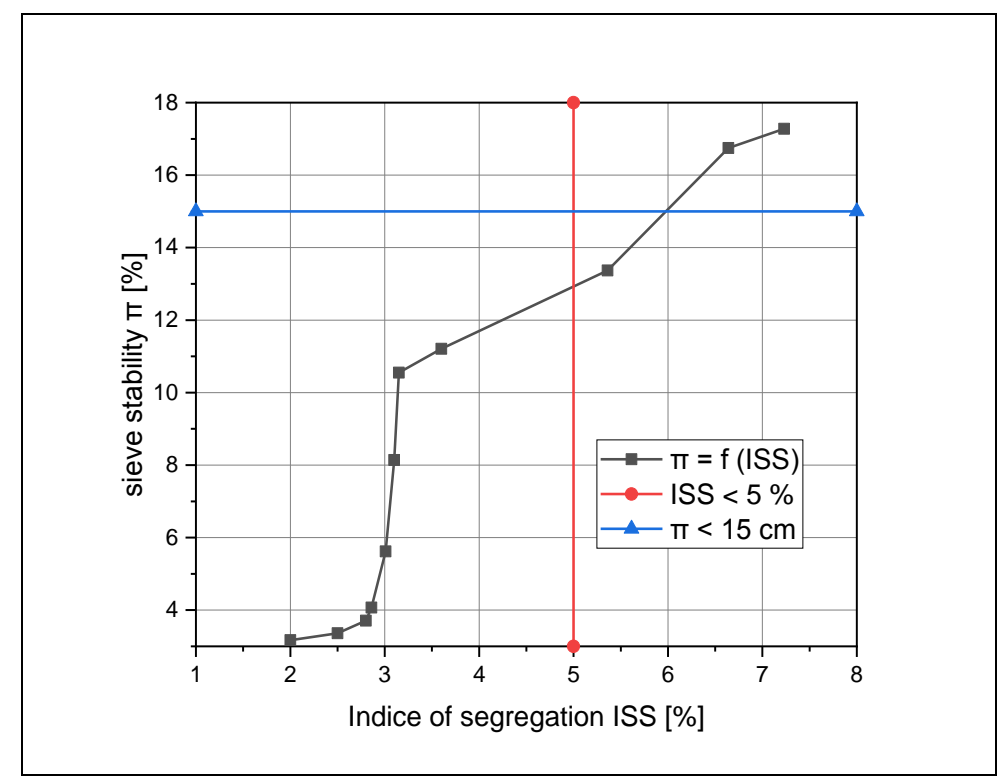

Fig 10. Sieve stability $\pi(\%)$ as a function of the static segregation index.

\subsection{Concrete in the hardened state}

After placing the concretes to be tested in their molds, the test specimens were kept in a humid room for a period of 24 hours. Once the specimens were demolded, they were stored in water at 
an ambient temperature of $20^{\circ} \mathrm{C}$. All measurements of compressive strength, ultrasonic pulse velocity and modulus of elasticity of concrete were carried out at 28 days.

Figure 11 groups the results of the compressive strength as a function of SSI for different mixtures of self-compacting concrete. The compressive strength values obtained were quite high; they exceeded $20 \mathrm{MPa}$. These values are good for structural concretes. However, the obtained results in the fresh state are to be excluded for formulations B9, B10 and B11.

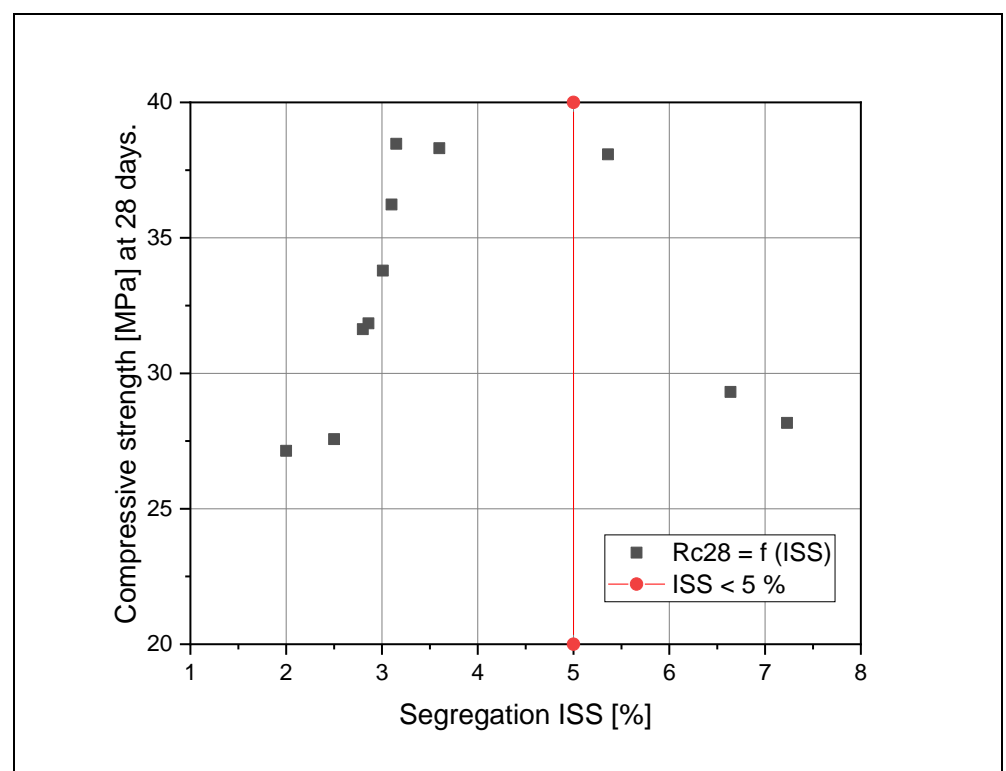

Fig 11. Evolution of the compressive strength as a function of the static segregation index.

Figure 12 illustrates the variation of the propagation speed of ultrasonic waves as a function of segregation, for different types of self-compacting concrete mixtures. It should be noted that the results of the ultrasonic pulse velocity test suggest that the reference SCCs, i.e. B 09, B10 and B11, had a low compactness in comparison with those of the other formulations. The substitution of $3 / 8$ by $8 / 15$ will increase the compactness by reducing the vacuum is vice versa (Figure 13).

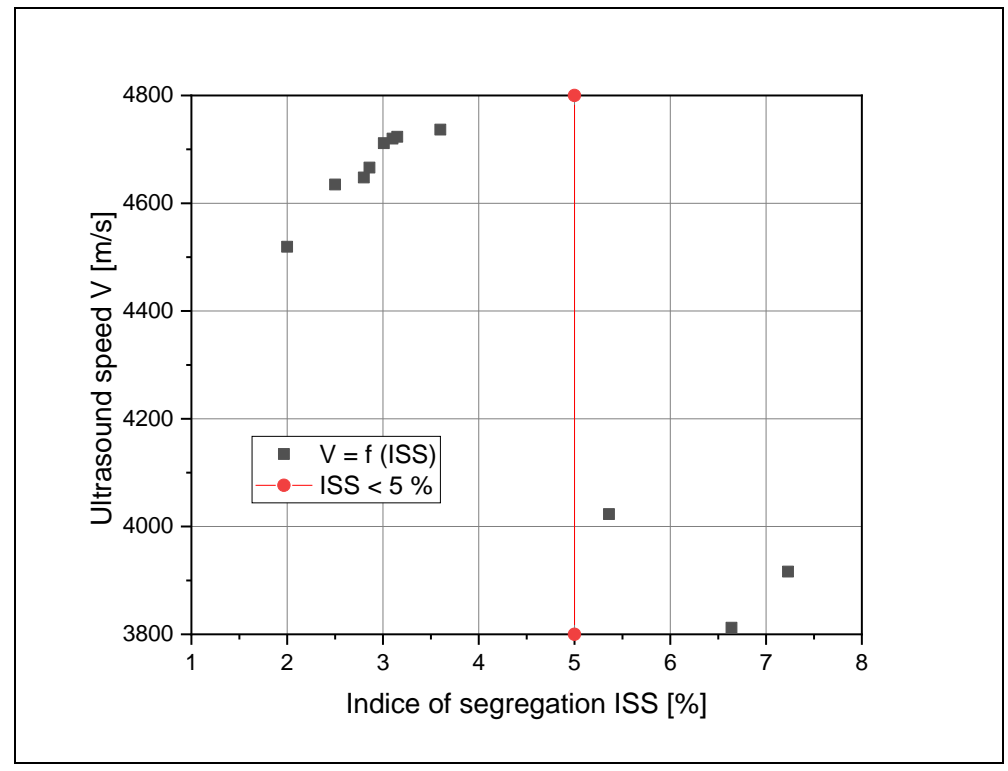

Fig 12. Propagation speed of ultrasonic waves in concrete as a function of SSI. 


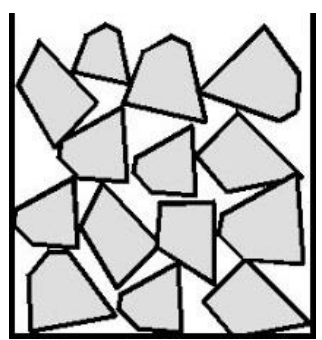

1- 8/15 and Sand

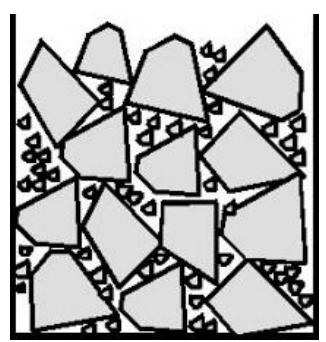

2- Gravel 8/15, 3/8 mm and Sand

Fig 13. Granular compactness.

Furthermore, Figure 14 depicts the evolution of the dynamic elasticity modulus as a function of segregation, for different types of self-compacting concrete mixtures.

In this study, a non-destructive test method and the density of self-compacting concrete were used to calculate the modulus of elasticity (Equation 02). This method proved to be effective for old structures still in use.

The dynamic elastic modulus can be determined by the following equation:

$$
E=V^{2} \times \rho \times \frac{(1+v) \times(1-2 v)}{(1-v)}
$$

Where $\rho$ is the density of concrete (experimental), $v=0.2$ is Poisson's ratio, and $V$ is the speed of sound [km/s].

Figure 14 indicates that a very high dynamic elastic modulus was obtained for different SCCs, at 28 days. The elastic modulus results are increasing if ISS $<5 \%$ for concretes B1 to B8 and decreasing if ISS $>5 \%$ for concretes B9 to B11. The decrease in these concrete performances is linked to two phenomena: bleeding and segregation.

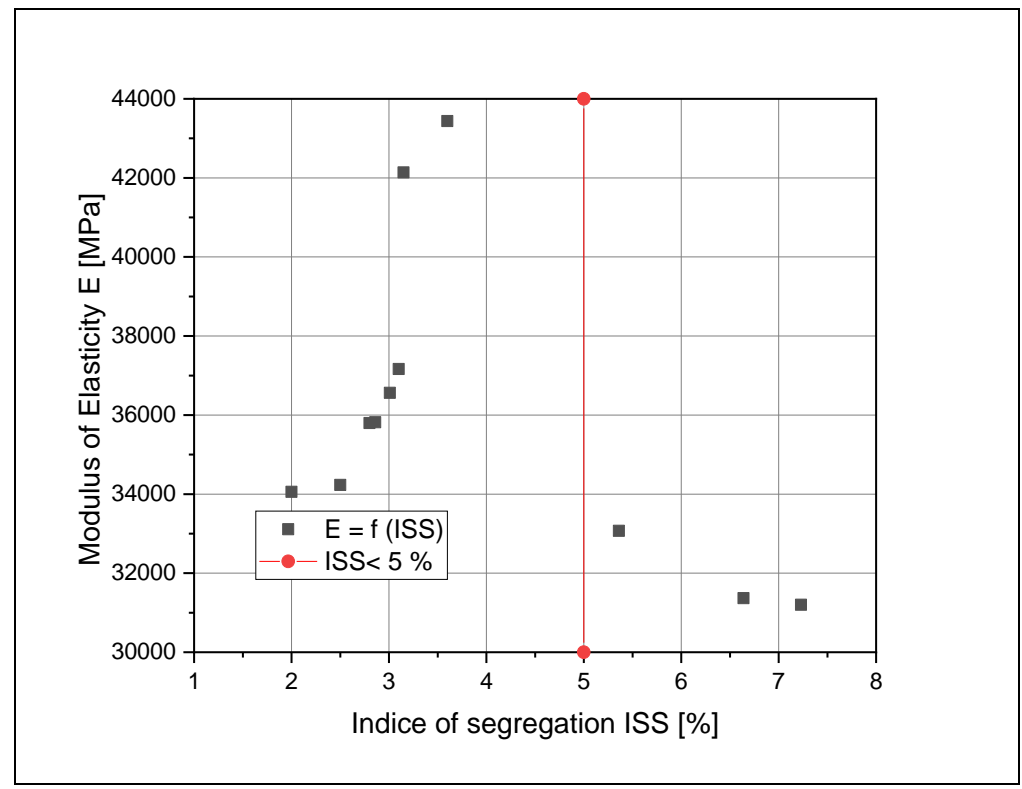

Fig 14. Modulus of elasticity of concrete as a function of the static segregation index.

\section{Conclusion}

This experimental study made it possible to highlight the influence of the granular mixture on SSI in the fresh state, and on the mechanical performance in the hardened state. The quantity of 
gravel of class $8 / 15$ was replaced by gravel of class $3 / 8$, at different percentages, to obtain a selfcompacting concrete with different granular distributions.

The main conclusions of this study are summarized in the following points:

- The results of the tests in the fresh state and in the hardened state indicated that the concretes B6, B7 and B8 proved to satisfy all the requirements, standards and recommendations of class $\mathrm{F} 6$.

- The reference granular mixtures, i.e. B2 to B5, exhibited the characteristics of selfcompacting concrete; these characteristics belong to different classes (from F2 to F5) according to Standard NF 206 (AFNOR, 2014). On the other hand, it was shown that the increase in the specific surface area had a significant effect on the quantity of mixing water absorbed, which had a remarkable impact on the results of the spreading and L-box tests.

- The formulations B9, B10 and B11 with a high percentage (greater than 80\%) of aggregates of class G 8/15 caused a discontinuation in the granular mixture, which engendered a large number of voids inside the self-compacting concrete; this could be confirmed by the ultrasonic pulse velocity test.

- $\quad$ All the granular mixtures of reference self-compacting concrete, from B1 to B11, possessed a compressive strength $(\mathrm{Rc}>20 \mathrm{MPa})$, as required by the seismic regulations.

- The ultrasonic testing revealed that the granular compactness decreases or increases depending on the quantity of aggregates of class G 8/15 used in concretes B9, B10 and B11. It should be noted that the porosity of self-compacting concrete depends on its granular compactness.

- This study allowed stating that to prepare self-consolidating concrete with acceptable static segregation index values as recommended by the AFGC regulations, the percentage of aggregates of class G $8 / 15$ should be limited to the range between $50 \%$ and $70 \%$, while this interval is between $30 \%$ and $50 \%$ for aggregates of class $\mathrm{G} 3 / 8$.

\section{References}

AFGC (2008), L'Association Française de Génie Civil, Recommandations pour l'emploi des Bétons Autoplaçants, document scientifique et technique.

ASTM C1610/C1610M-10 (2010). Test method for static segregation of self-consolidating concrete using column technique.

ASTM C1712-09 (2009). Test method for rapid assessment of static segregation resistance of selfconsolidating concrete using penetration test.

Bensebti, S., Chabane, A., Aggoun, S., \& Houari, H. (2015) la ségrégation verticale dans les bétons autoplaçants, Mise en place d'une procédure expérimentale, Rencontres Universitaires de Génie Civil, May, Bayonne, France.

Bui, V. K., Montgomery, D., Hinczak, I., \& Turner, K. (2002). Rapid testing method for segregation resistance of self-compacting concrete. Cement and Concrete research, 32(9), 1489-1496.

Fujiwara, H. (1992). Fundamental study on the self-compacting property of high-fluidity concrete. Proc Japan Concr Inst, 14(1), 27-32.

NF EN 12350-10, (2010), Essai pour béton frais - Partie 10 : béton auto-plaçant - Essai à la boîte en L. AFNOR, P18-431-10.

NF EN 12350-11, (2010), Essai pour béton frais - Partie 11 : béton auto-plaçant - Essai de stabilité au tamis, AFNOR, P18-431-11.

NF EN 12350-8, (2019). Essais pour béton frais - Partie 8 : béton auto-plaçant - Essai d'étalement au cône. AFNOR, P18-431-8. 
Otsuki N., Hisada M., Nagataki S., Kamada T., (1996) "An experimental study on fluidity of antiwashout underwater concrete", ACI Materials Journal, 93, 1,20-25.

Shen, L., Jovein, H. B., \& Li, M. (2014). Measuring static stability and robustness of self-consolidating concrete using modified Segregation Probe. Construction and Building Materials, 70, 210-216..

Sidky, M., Legrand, C., \& Barrioulet, M. (1981). Influence de la concentration en granulats et du temps de vibration sur la ségrégation interne dans le béton frais. Matériaux et Construction, 14(5), 367377.

Tangtermsirikul, S., Sakamoto, J., Shindoh, T., \& Matsuoka, Y. (1991). Evaluation of resistance to segregation of super workable concrete and the role of a new type of viscosity agent. Reports of the Technical Research Institution, 24, 369-376.

Trudel (1995), Mise au point d'un essai rapide de mesure de la résistance à la ségrégation du béton frais, rapport de stage, Université de Sherbrooke, Québec, Laboratoire Central des Ponts et Chaussées, 122 pages.

Umehara, H., Uehara, T., Enomoto, Y., \& Oka, S. (1994). Development and usage of lightweight high performance concrete. In Proceedings of International Conference on high Performance Concrete (supplementary papers), Singapore, American Concrete Institute, Detroit, MI, USA, pp. 339-353.

Yim, H. J., Bae, Y. H., \& Kim, J. H. (2020). Method for evaluating segregation in self-consolidating concrete using electrical resistivity measurements. Construction and Building Materials, 232, 117283. 